\title{
Large diverticulum of the urinary bladder: A rare cause of deep vein thrombosis with consecutive pulmonary embolism
}

\author{
Oliver Zimmermann, MD; ${ }^{* 1}$ Jan Torzewski, MD; ${ }^{* 1}$ Ekkehard Reichenbach-Klinke, MD; ${ }^{\dagger 1}$ Christine Zenk, $M D^{\$ 1}$
}

*Cardiovascular Center Oberallgäu Kempten, Hospital Immenstadt, Germany; ${ }^{\dagger}$ Clinic for Urology, Immenstadt, Germany; §Department of Internal Medicine, Hospital Immenstadt, Germany; ${ }^{\text {Under the }}$ direction of SANA Kliniken AG.

Cite as: Can Urol Assoc J 2015;9(5-6):E321-3. http://dx.doi.org/10.5489/cuaj.2533

Published online May 13, 2015.

\section{Abstract}

A 73-year-old man was admitted with progressive dyspnea; he also had benign prostatic hyperplasia (BPH). An angio computed tomography scan showed pulmonary embolism with thrombi in both main pulmonary arteries. By duplex ultrasonography, we detected a thrombus in the right vena femoralis superficialis and vena femoralis communis. Simultaneously, we also noticed a large diverticulum on the right side of the urinary bladder and urinary stasis II of the left kidney. We consider the BPH as the trigger for a secondary diverticulum of the urinary bladder. As a result of its large dimensions, mechanical compression of the deep right pelvic veins resulted in thrombosis which finally caused the pulmonary embolism. With respect to the urinary stasis II, surgical excavation of the diverticulum with infravesical desobstruction was planned. The potentially lethal course of large diverticula may require surgery.

\section{Introduction}

Immobilization, surgical procedures, malignoma and disturbance of coagulation represent common causes of deep vein thrombosis with consecutive pulmonary embolism. We report a case of a patient with a large diverticulum of the urinary bladder, which resulted in a mechanical compression of the deep inguinal and pelvic veins with consecutive thrombosis and pulmonary embolism. This fulminant and potentially lethal complication is unique and may be one more reason to refer large diverticula to surgery.

\section{Case report}

A 73-year-old man was admitted with progressive dyspnea that lasted for 12 weeks. He also had benign prostatic hyperplasia (BPH) which was treated by medication. The patient presented with exspiratory rales over both lungs and was in a cardiopulmonary stable condition. An electrocardiogram (ECG) showed a sinus rhythm with a heart rate of 109/min, left anterior fascicular block, and complete right bundle branch block. The echocardiography also revealed signs of right ventricular dysfunction with a tricuspid valve insufficiency grade I and II and a pressure gradient of $55 \mathrm{mmHg}$. The clinical chemistry revealed a slightly elevated C-reactive protein of $14.50 \mathrm{mg} / \mathrm{L}(<5.00 \mathrm{mg} / \mathrm{L})$, a low-density lipoprotein of $466 \mathrm{U} / \mathrm{L}$ (range: 135-225 U/L), a hs-Troponin T of $21.85 \mathrm{pg} / \mathrm{mL}(<14.00 \mathrm{pg} / \mathrm{mL})$, a N-terminal pro-brain natriuretic peptide (NT-pro BNP) of $3457 \mathrm{pg} / \mathrm{mL}(<241 \mathrm{pg} / \mathrm{mL})$, and a D-dimer of $5.97 \mu \mathrm{g} / \mathrm{mL}(<0.50 \mu \mathrm{g} / \mathrm{mL})$. An angiocomputed tomography scan detected pulmonary embolism with thrombi in both main pulmonary arteries (Fig. 1, part A). A duplex ultrasonography of the leg veins showed an organized thrombus in the right vena femoralis superficialis and vena femoralis communis (Fig. 1, part B). Simultaneously, a large diverticulum on the right side of the urinary bladder with an estimated volume $>600 \mathrm{~mL}$ after micturition was seen. A narrow communication of the diverticulum with the urinary bladder (i.e., the neck) was found (Fig. 1, part C). The left kidney presented with a urinary stasis II. Finally, the prostate gland was enlarged with a volume of $56 \mathrm{~mL}$.

We initiated intravenous anticoagulation with unfractionated heparin and switched to oral anticoagulation with rivaroxaban $15 \mathrm{mg}$ bid. Compression therapy was performed using tights. No medical thrombolysis was considered as (i) clinical symptoms started at least 12 weeks before and the venous thrombus was organized; (ii) the patient was always clinically stable; and (iii) he recovered quickly and was mobile soon after with no limitations. Furthermore, acute signs of cardiac dysfunction (e.g., elevation of hsTroponin $T$ and NT-pro-BNP levels) were marginal only. Additionally, under the initial therapy with heparin, gross hematuria was observed.

Overall we think that the patient's BPH triggered the secondary diverticulum on the right side of the urinary bladder. Its large dimensions compressed the deep right inguinal and pelvic veins which resulted in thrombosis which finally 

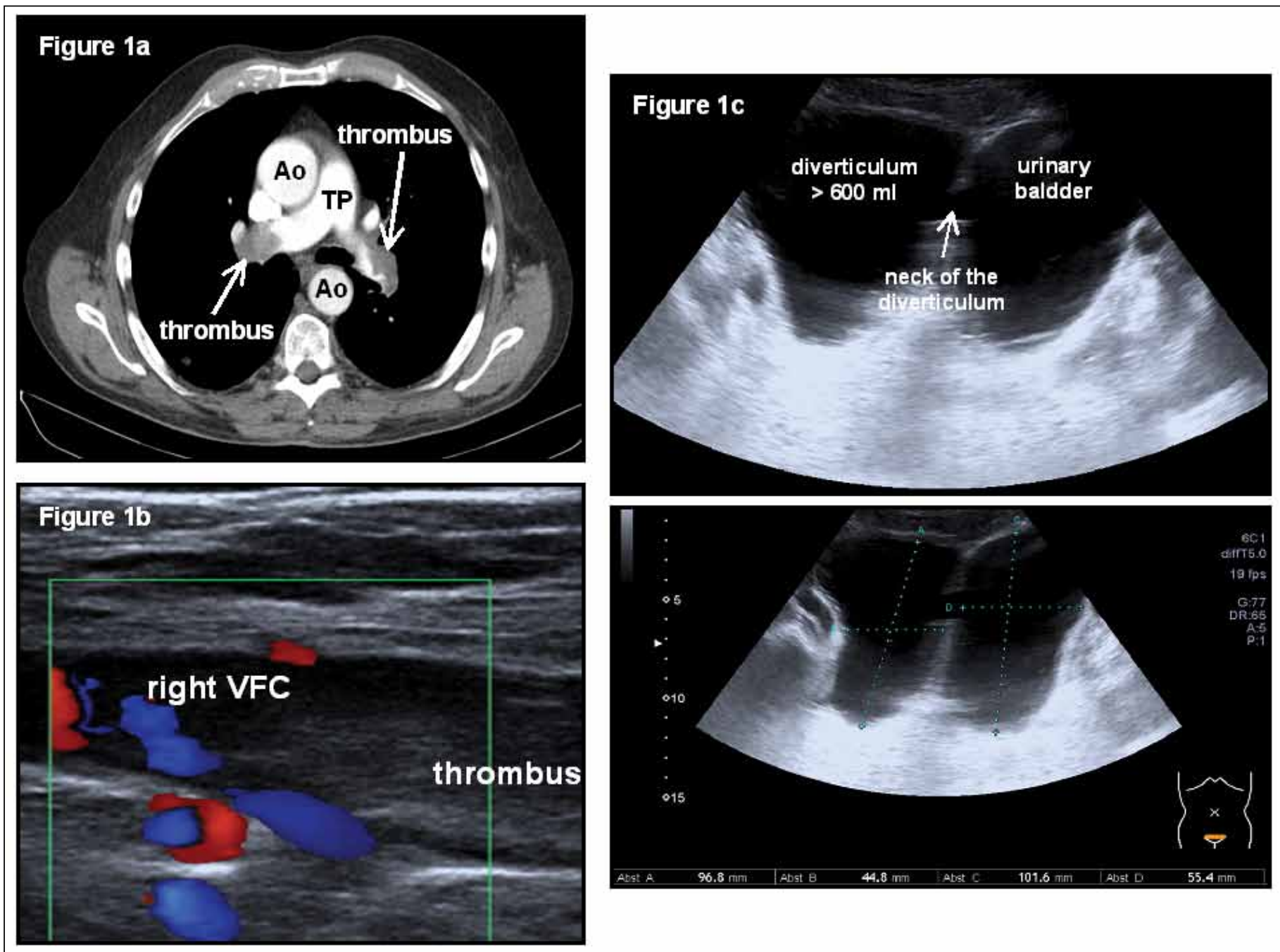

Fig. 1. A: Computed tomography angiography demonstrates large thrombus formation in both pulmonary arteries. B: Duplex ultrasonography could detect a large and organized thrombus in the vena femoralis communis (VFC) and Vena femoralis superficialis on the right side. C: B-scan sonogram of the pelvis demonstrates a large diverticulum on the right side of the urinary bladder. The narrow communication between bladder and diverticulum i.e. the neck is illustrated. The diameter of the bladder was $102 \times 55 \mathrm{~mm}$ and $97 \times 45 \mathrm{~mm}$ for the diverticulum. The volume of the diverticulum was calculated to be $>600 \mathrm{~mL}$. The urinary bladder was characterized by its thick wall in contrast to the diverticulum. Ao: aorta, TP: truncus pulmonalis.

caused pulmonary embolism. Surgery was mainly planned because of the compression of the deep pelvic veins and the danger of recurrent pulmonary embolism with a potentially lethal outcome. in addition to the first indication, the urinary stasis and renal impairment were also a factor. Excavation of the diverticulum and simultaneous infravesical desobstruction was considered. The surgery however was not possible because the patient was taking oral anticoagulation therapy, so it was scheduled for a later date. The patient recovered quickly and was discharged 6 days after admission. To the best of our knowledge, there is no other similar case.

\section{Discussion}

Primary diverticula of the urinary bladder are rare and may occur as a result of a congenital deficiency in bladder mus- culature. Aquired or secondary diverticulua are more frequent and commonly associated with neurogenic bladder abnormalities or chronic outflow obstruction. Patients with $\mathrm{BPH}$ make up $25.3 \%$ of those affected with secondary diverticula; this number is $13.8 \%$ among men aged 40 to 49 and $43 \%$ in men aged 60 to $69 .{ }^{1}$ Secondary diverticula represent herniation of the mucosa and submucosa through the muscular wall of the urinary bladder and are often located at the lateral side. ${ }^{2}$ As this anatomy is typical for acquired diverticula, they are called pseudo-diverticula. In these cases, not all parts of the bladder wall are involved in the formation of the diverticulum. As the muscle layer is not involved, urinary stasis is created because the contractility is missing. In prostatism, the incidence of urinary bladder diverticula is about $50 \%$ when the diagnosis is based on cystography; this number is much lower when urography or cystoscopy 
is used. ${ }^{3,4}$ The pathomechanism of diverticula sets the maleto-female ratio at 9:1. ${ }^{5}$ Mostly urinary baldder diverticula remain asymptomatically, but in some patients infection, stone formation, rupture, or cancer are described as rare complications, especially in narrow-necked diverticula. ${ }^{3,6-10}$ There are also reports that diverticula of the urinary bladder could be part of a femoral hernia. ${ }^{10}$

As seen in our patient, diverticula are often related to age and upper urinary tract dilatation (e.g., urinary stasis with the danger of renal impairment). ${ }^{3,4}$ Most clinicians agree that surgery is indicated in complicated diverticula. It seems reasonable that next to diverticulectomy the associated subvesical obstruction should be eliminated simultaneously. This concept was also planned for our patient, but it was postponed due to the patient's uninterrupted oral anticoagulation within the first months after his diagnosis of severe pulmonary embolism.

\section{Conclusion}

To our knowledge the mechanical compression of the deep inguinal and pelvic veins with consecutive thrombosis and pulmonary embolism has never been reported before as a fulminant complication of a diverticulum of the urinary baldder. The potentialy leathal course of a common and usually harmless diagnosis may represent one more reason to refer large diverticula to surgery.

Competing interests: The authors declare no competing financial or personal interests.
This paper has been peer-reviewed.

\section{References}

1. Garraway WM, Collins GN, Lee RJ. High prevalence of benign prostatic hypertrophy in the community. Lancet 1991;338:469-71. http://dx.doi.org/10.1016/0140-6736(91)90543-X

2. Dunnick NR, Sandler CM, Newhouse JH. Textbook of Uroradiology. 5th edition, Philadelphia, PA: Lippincott Williams \& Wilkins; 2013:285-6.

3. Shakeri $S$, Rasekhi AR, Yazdani $M$, et al. The incidence of diverticula of urinary bladder in patients with benign prostatic hypertrophy and the comparison between cystoscopy and cystography in detecting bladder diverticula. IRCMJ 2007;9:36-41.

4. Quirinia A, Hoffmann AL. Bladder diverticula in patients with prostatism. Int Urol Nephrol 1993;25:243-7.

5. London RL. Diverticulum of the urinary bladder. Am Fam Physician 1984;30:151-3.

6. Ajwani VR, Bharaney RP, Singh V, et al. Large vesical diverticulae with narrow neck, presenting with features of severe urinary tract infection managed surgically. Indian I Surg 2013;75:327-8. http:// dx.doi.org/10.1007/s12262-012-0465-0

7. Idrees MT, Alexander RE, Kum JB, et al. The spectrum of histopathologic findings in vesical diverticulum: Implications for pathogenesis and staging. Hum Pathol 2013;44:1223-32. http://dx.doi. org/10.1016/i.humpath.2012.11.005

8. Leahy 0 , Grummet J. Splash! The spontaneous rupture of a bladder diverticulum: a rare cause of an acute abdomen. ANZ J Surg 2013;83 :792-3. http://dx.doi.org/10.1111/ans.12240

9. Manfredelli S, Zitelli A, Pontone $S$, et al. An inguinal bladder diverticulum. Case report of a rare finding in a recurrent inguinal hernia. Ann Ital Chir 2012;26. pii:S2239253X12019810

10. Omari AH, Alghazo MA. Urinary bladder diverticulum as a content of femoral hernia: a case report and review of literature. World J Emerg Surg 2013;8:20. http://dx.doi.org/10.1186/1749-7922-8-20

Correspondence: Dr. Oliver Zimmermann, Cardiovascular Center Oberallgäu-Kempten, Hospital Immenstadt, Teaching hospital of Ulm University, under the direction of SANA Kliniken AG, Im Stillen 3, 87509 Immenstadt, Germany; oli.zimmermann@gmx.de 